\title{
Field-scale in Situ Measurements of Vadose Zone Flow and Transport Using Multiple Tracers at INEEL Vadose Zone Research
}

AWARD NUMBER: DE-FG07-02ER63508

AWARDEE NAME: University of New Mexico, Yemane Asmerom UNM PI

PROJECT OR AWARDEE ACCOUNT NO.: EMSP 86679

Final Report

Robert C. Roback, LANL \& Yemane Asmerom UNM

April 14, 2006

\section{$\underline{\text { Purpose }}$}

Vadose zone contamination is a legacy of DOE operations over the past 50 years and is a problem throughout the complex, including the Idaho National Engineering and Environmental Laboratory (INEEL). This project is being conducted at the INEEL Vadose Zone Research Park (VZRP), utilizing the infiltration ponds as well as flow in the Big Los River to study the effects of fluid flux, water chemistry, and degree of saturation on contaminant transport within the vadose zone. This study is aimed at gaining a better understanding of vadose zone flow and transport processes at the field scale and establishing defensible links between laboratory- and field-derived transport parameters. The subsurface geology and hydrology at the study site are very similar to those at the contaminated sites at INEEL. Therefore, conceptual models and quantitative parameters of flow and transport determined during this study will be directly applicable to the contaminated sites. This study will provide important data to help understand contaminant transport locally and globally.

\section{Approach}

- Simultaneous injection of multiple tracers into infiltration ponds and Big Lost River

- Interpretation and modeling of spatial and temporal patterns in tracer recovery for conservative, reactive, and colloidal tracers

- Analysis of natural U and Sr concentration and isotopic composition (by TIMS) to provide element-specific transport parameters for these contaminants of concern

- Integration of tracer recovery data with data from tensiometers, water levels, and geophysics

- Laboratory experiments to determine transport parameters for comparison to field results 


\section{Division of Responsibilities}

UNM: Sr and U-series isotopic work on all relevant materials and related laboratory work.

LANL: Other tracer work and related laboratory work.

Principal Investigators: Robert C. Roback - LANL; Larry Hull - INEEL; Yemane Asmerom - UNM Key Personnel: Catherine Jones: LANL employee and Ph.D. candidate at New Mexico Tech under supervision of Robert Bowman; Paul Reimus and Jeri Sullivan: project participants at LANL; Travis McLing: primary project participant at INEEL; Kristine Baker: collaborator at INEEL; UNM: Elizabeth Nichols: MS student at UNM under supervision of Yemane Asmerom.

\section{Technical Progress}

The project entitled "Field-scale in situ measurements of vadose zone flow and transport using multiple tracers at INEEL Vadose Zone Research Park (VZRP)" (EMSP5-02-06), was initiated in October of 2002 and is scheduled to end in September 2005. This current study, along with hydrologic and geophysical studies described in the previous section were the first scientific investigations conducted at the VZRP, and as such provide the framework on which current knowledge and subsequent studies are based.

Infiltration ponds at the VZRP were activated in August 2002, several months earlier than expected and two months before EMSP funds were in place. Due to the early filling of the ponds, tracer permits were not obtained in time to inject tracers during this initial filling. However, LANL and INL did manage to procure emergency funds to conduct a sampling campaign. Hundreds of samples were collected and most are now analyzed for major cations and anions and a subset of these for $\mathrm{Sr}$ and $\mathrm{U}$ isotope ratios.

Tracer injection permits were obtained in early 2003. Two major tracer tests were conducted during 2003. Test 1 was conducted under conditions approaching steady state flow into the south pond during June and July 2003. The test consisted of injection of $\sim 19 \mathrm{~kg}$ of 2,4,5-TFBA and subsequent collection over next month of $>1200$ samples from monitoring wells and lysimeters. Analyses for tracer are complete. Analyses for cations and $\mathrm{U}$ and $\mathrm{Sr}$ isotopes are ongoing. Test 2 was conducted in the north pond and coincided with a planned switch of the discharge water from the south pond. Injection of tracer was coincident with wetting of the north pond, which had been dry for almost a year. Tracer consisted of $\sim 25 \mathrm{~kg}$ of $\mathrm{KBr}$ and $\sim 21 \mathrm{~kg}$ of 2,4,-DFBA injected simultaneously. Over 3000 samples were collected over the next two months. Analyses for tracer are complete. Samples were also collected for determination of colloid concentrations and particle size distribution. A subset of samples has been analyzed for ${ }^{234} U /{ }^{238} U$ and ${ }^{87} \mathrm{Sr}{ }^{86} \mathrm{Sr}$ isotope analyses.

Several additional studies designed to aid in interpreting field data have been conducted or are underway. These studies include:

1. Sorption batch test were conducted on the 2,4-DFBA used for the 2003 tracer studies. Given the assumptions that the FBA's are conservative it was important to demonstrate that this was true in the VZRP surface alluvium. Results indicate that over the time period and concentration range utilized for the study the 2,4-DFBA is indeed conservative.

2. Core samples from the VZRP were described and samples were collected for laboratory characterization and sequential leaching studies. Sequential leaching experiments are being conducted to determine the origin and evolution of uranium and strontium measured in groundwater samples (Nichols, et al., 2005). Samples include alluvium, interbed sediments, and basalt with varying amounts of fracturing, and alteration. The leaching procedure is designed to extract $\mathrm{U}$ and $\mathrm{Sr}$ from the water-soluble and exchangeable phases, carbonates, $\mathrm{Fe}$ and $\mathrm{Mn}$ oxides, organics, and the residuals. 
3. During June of 2004, water samples from 3 wells completed in perched water zones at different depths were collected for the purpose of characterizing natural colloids.

Continuing analysis and modeling of data have improved our conceptual model of flow and transport at the site and provided site-specific transport parameters. A numerical model using the Finite Element Heat and Mass (FEHM) transfer code is being developed.

\section{Discussion of Significant Results}

The two tracer tests conducted during the summer of 2003 yielded data sets that provide high-resolution information regarding transport through three hydrogeologic units, for a range of vertical and lateral distances, and under both quasi-steady-state and transient flow conditions. In addition, because two conservative tracers with different molecular diffusion rates were used, analysis of these data provides insight into mechanisms of mass transfer between flow domains. Test 2 produced complete to nearly complete tracer recovery curves for $\mathrm{Br}^{-}$and 2,4-DFBA in seven monitoring wells and two lysimeters. Bromide breakthrough curves are shown in Figure 5.

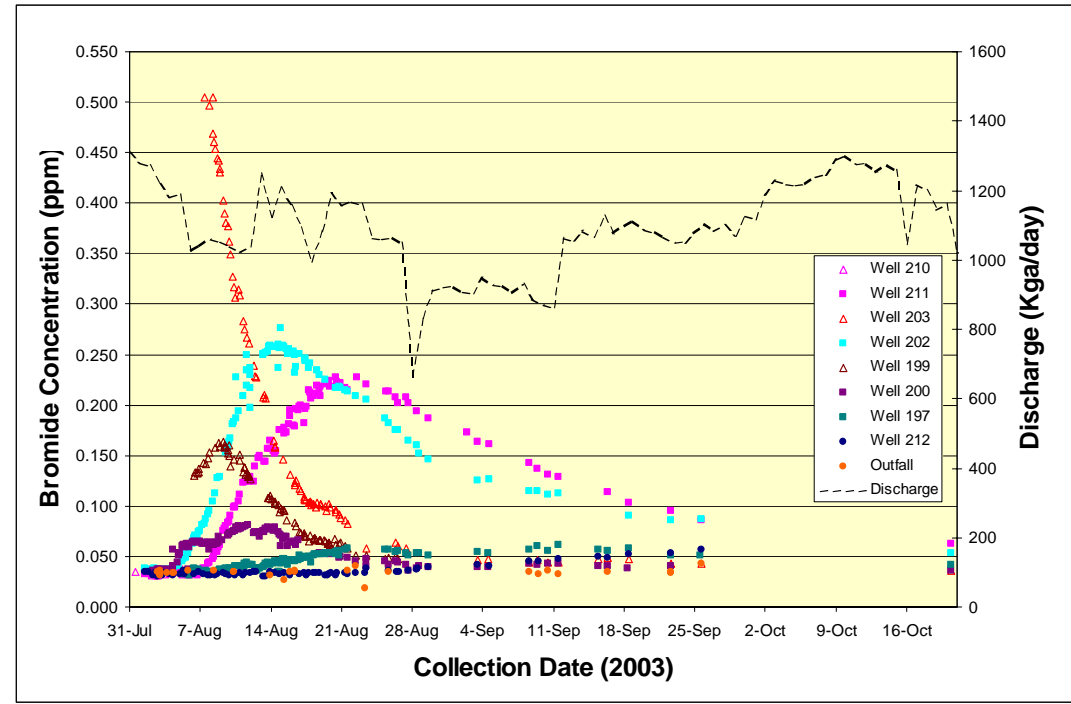

Figure 5. Recovery curves of $\mathrm{Br}^{-}$for all water-producing wells at the VZRP. Daily discharge during the test is also shown.

Breakthrough curves (BTCs) from the alluvial wells yielded information regarding flow and transport in the surficial alluvium. Data from the deeper wells provide information regarding flow through the integrated alluvium/basalt complex. Flow and transport characteristics of the fractured basalt may be backed out from these integrated BTCs. The data allow evaluation of transport through the interbedded sediments by comparing breakthrough at wells finished above the interbed with breakthrough in lysimeters finished within and below the interbed. Similarly, the data yield valuable information on the relative magnitudes of dispersivity between geologic units, and as a function of saturation and of flow transients.

A feature that is common to all the BTCs generated in this study is that mass recovery is heavily skewed toward the tailing end (Fig. 5). This is a widespread observation in BTCs representing transport through heterogeneous media and is often attributed to matrix diffusion. However, researchers have suggested several other conceptual models over the last two decades including: diffusion between flowing and stagnant domains within the fracture plane and heterogeneous advection in which tailing in BTCs is explained by breakthrough from multiple preferential pathways contributing to one, integrated 
breakthrough curve. The fundamental difference between these possible scenarios is whether diffusion plays a significant role in mass transfer between flow domains, or whether tailing is purely an advective process. This distinction is very important for predicting contaminant transport.

Test 2 was designed to address issues pertaining to the development of multiple flow domains and the mechanism of mass transfer between them. In test 2 we used $\mathrm{Br}$ and 2,4-DFBA as tracers. These two molecules have molecular diffusion rates of $2.0 \times 10^{-5}$ and $7.6 \times 10^{-6} \mathrm{~cm}^{2} / \mathrm{s}$ respectively. Figure 6 shows the test 2 breakthrough of bromide and 2,4-DFBA in wells 202 and 211. Well 202 is closer to the discharge point, and the two BTCs show no separation. In contrast, the two BTCs from well 211 (laterally more distant from the discharge point and thus dominated by saturated flow) show some separation in breakthrough time and concentration consistent with a diffusive mass transfer between multiple flow domains.
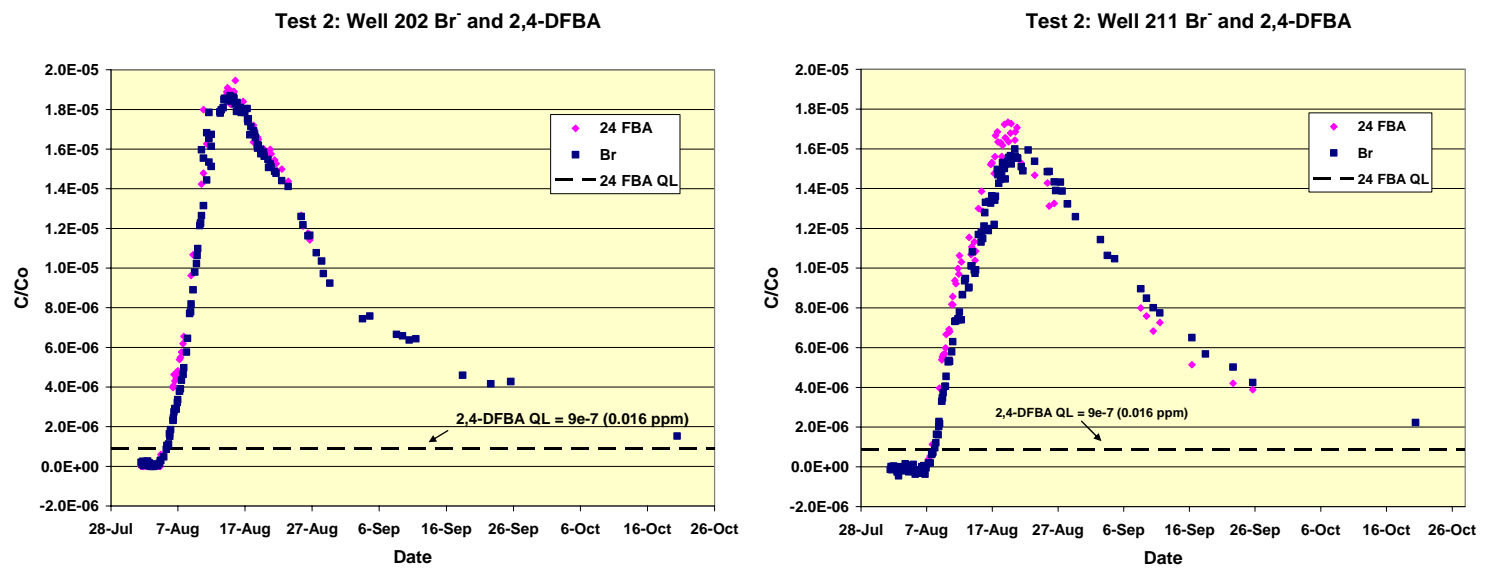

Figure 6: Breakthrough curves from test 2 showing different $\mathrm{Br}^{-}$vs. 2,4-DFBA behavior in two wells. In well 202 there is no separation of the two BTCs suggesting an advectively dominated tailing mechanism. In contrast, in well 211 the 2,4-DFBA breaks through sooner and at a higher concentration that the $\mathrm{Br}^{-}$ suggesting that diffusion plays a more important role in mass transfer along the preferential flow paths.

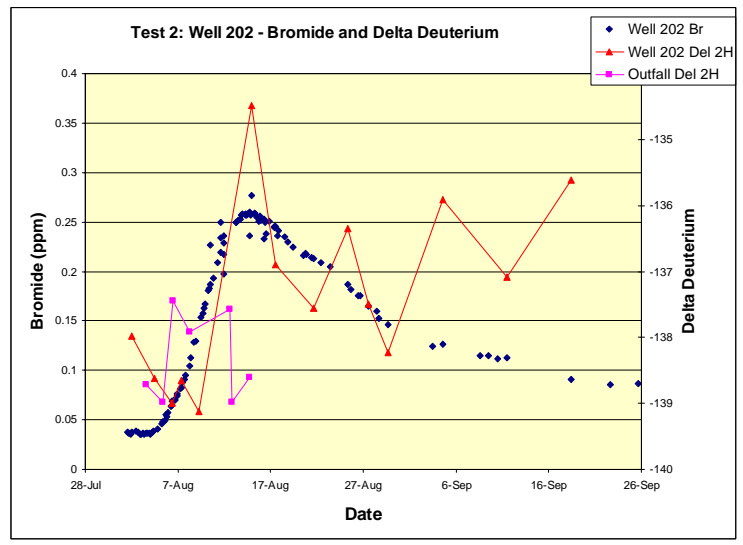

Figure 7. Test $2 \mathrm{Br}^{-}$breakthrough curve for well 202 and $\delta^{2} \mathrm{H}$ for well 202 and outfall samples

Samples for stable isotope analyses were collected throughout test 2 from all monitoring wells and lysimeters. Because hydrogen and oxygen are part of the water molecule, they provide another conservative tracer to help evaluate flow and transport at the site. Figure 7 shows hydrogen isotope ratios (as $\delta^{2} \mathrm{H}$ ) plotted against the Br recovery curve and the colloid concentration curve for well 202 during test 2. The plot shows that the deuterium signal of sampled water is distinct from that of the outfall shortly after first arrival of the $\mathrm{Br}^{-}$with the maximum difference at the peak of $\mathrm{Br}^{-}$recovery. The $\mathrm{Br}^{-}$tracer was 
introduced with the initial pulse of water into the relatively dry vadose zone beneath the north pond. It is expected that resident porewater consists of a mixture of water derived from natural infiltration and water input into the north pond during a brief test of the system one year earlier. A reasonable explanation for the data is that deviations in $\delta^{2} \mathrm{H}$ from values of the outfall are due to mixing of variable amounts of porewater with outfall water. The fact that the $\mathrm{Br}^{-}$breakthrough curve is smooth indicates that bromide concentrations in the porewater are small relative to those of the tracer-bearing water so that varying proportions of porewater have little effect on $\mathrm{Br}^{-}$concentrations in the samples. Measured $\mathrm{Br}^{-}$ concentrations in porewater, which are typically below detection of $0.016 \mathrm{ppm}$ are consistent with this assertion. Interestingly, deuterium concentrations remain different from those of the outfall for many samples well past the peak of the tracer pulse. This indicates that vadose-zone porewater continued to be mixed with outfall water for at least six weeks after initial filling of the north pond.
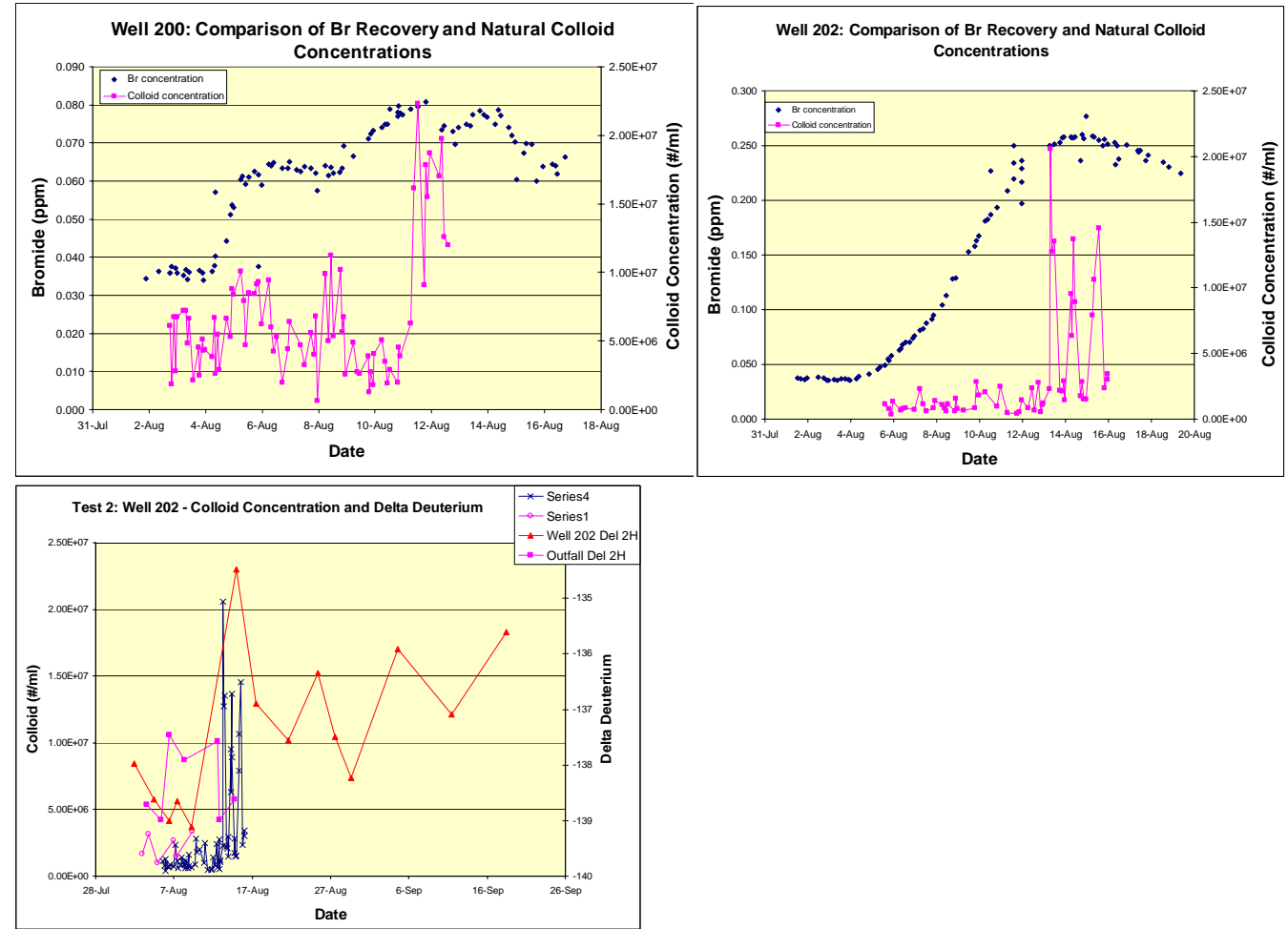

Figure 8. Plots of Br- concentration and colloid concentration for wells 200 and 202 (upper panels) and $\delta^{2} \mathrm{H}$ and colloid concentration for well 202 and outfall samples (lower panel). All data are from test 2.

\section{Colloids}

Colloids were also collected from wells 200 and 202 during test 2. These wells were selected because they were producing water prior to the test and consistent sampling conditions could be maintained throughout the sample collection. Colloids were collected in Teflon bottles, refrigerated, and analyzed within a few weeks for total particle (50 to $1000 \mathrm{~nm}$ ) concentration and particle size distribution. Colloid concentrations in monitoring wells are elevated above those in the outfall (Figure 8) indicating colloid release along the flow pathways. Peaks in colloid concentrations in both wells coincide with peaks in $\mathrm{Br}^{-}$ concentration suggesting enhanced colloid release during initial wetting. Multiple spikes in colloid concentrations are puzzling. They do not correlate with tracer recovery curves, water level curves, or discharge volumes. Peak colloid concentrations do coincide with the spike in deuterium concentration for well 202. As discussed above, excursions of the deuterium data from compositions of the outfall are interpreted to indicate varying proportions of porewater in the sample as a result of preferential flow. Colloids tend to concentrate along air-water interfaces. Wetting along preferential flow pathways would flush these air-water interfaces and release colloids into the perched water where wells 200 and 202 are 
completed. In this model, the spikes in colloid concentration represent connection of a preferential vadose-zone pathway to the saturated perched zone, which wells 200 and 202 sample. Once connected, the preferential flow zone is flushed of porewater and allows rapid flow of outfall water to the perched zone.

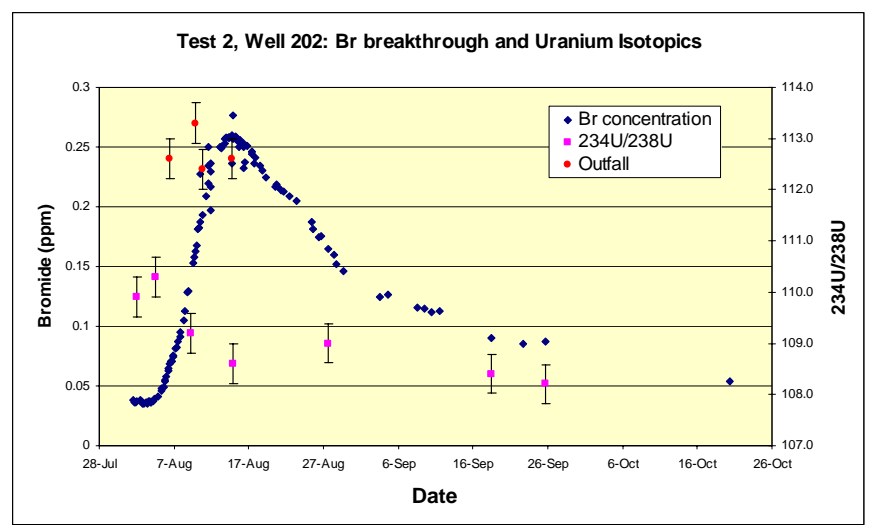

Figure 9. Test $2 \mathrm{Br}$ breakthrough curve for well 202 and ${ }^{234} \mathrm{U} /{ }^{238} \mathrm{U}$ isotope ratios for well 202 and outfall samples. Two-sigma uncertainties are shown for the isotopic data.

\section{Strontium and Uranium Isotopes}

Uranium and $\mathrm{Sr}$ concentrations and ${ }^{87} \mathrm{Sr} /{ }^{86} \mathrm{Sr},{ }^{234} \mathrm{U} /{ }^{238} \mathrm{U}$ isotope ratios in perched water are used to examine transport processes at the uncontaminated VZRP. These processes are expected to be similar to those that influence $\mathrm{U}$ and ${ }^{90} \mathrm{Sr}$ mobilization at the RWMC and INTEC. Analyses of outflow and perched water samples show isotopic compositions that range between those of the outflow water and one or more end members at depth. Water samples taken from well 202 during test 2 show variations in ${ }^{234} \mathrm{U}{ }^{238} \mathrm{U}$ that correspond with $\mathrm{Br}^{-}$breakthrough (Figure 9). The uranium isotope ratios are not equivalent to those of the outfall water during the sampling period. Interestingly, these samples also show essentially no change in uranium concentration. These data are interpreted to indicate: 1) the lithologic material provides a source of readily available uranium that has been added to the infiltrating water throughout the two-year operation of the infiltration ponds; 2) initial wetting of previously dry vadose zone during test 2 resulted in greater release of uranium from lithologic materials; and, 3) because uranium concentrations remained relatively constant during the test, the amount of uranium released to the infiltrating water was balanced by uranium removed from the infiltrating water onto the lithologic material. This type of natural attenuation would be undetectable without isotopic analyses. ${ }^{87} \mathrm{Sr} /{ }^{86} \mathrm{Sr} v$ s. ${ }^{234} \mathrm{U} /{ }^{238} \mathrm{U}$ for all samples gives a reaction path model between two end members, the outflow water and another member.

Information gained from field tests allows us to refine conceptual models of flow and transport at the INL. Important elements of these conceptual models include:

1. Flow in the alluvium is heterogeneous. Geochemical evidence indicates that the early wetting front is characterized by preferential flow zones.

2. A conceptual model in which water flow follows preferential flow zones in the vadose zone and flushes resident porewater is consistent with the tracer, colloid, stable, and radiogenic isotope data. To our knowledge this is the first documentation of these processes with multiple data sets in a field-scale tracer test.

3. Lateral flow along the alluvium/basalt contact is common. This may occur as an unstable unsaturated front or as saturated flow, depending on antecedent conditions.

4. Lateral flow along the alluvium/basalt contact is limited; the bulk of the water moves vertically across the contact and accesses flow pathways through fractures in the basalt. Flow through the basalt is essentially vertical until water arrives at relatively impermeable interbedded sedimentary 
layers where there is significant lateral flow. Significant saturated zones exist along the contacts between the basalt and sedimentary interbeds.

5. Highly permeable basalt rubble zones exist above the interbed that facilitate lateral transport

6. Flow through the interbed is slow relative to flow above the interbed.

Flow parameters for the surficial alluvium and the alluvium/basalt complex were derived by inversely fitting the BTCs to the 1-D advection dispersion equation using CXTFIT. The results of this modeling are:

1. Seepage velocity (v):

a. in the alluvium $40 \mathrm{~m} /$ day in test 1 and $9 \mathrm{~m} /$ day in test 2

b. in the basalt/alluvium complex $13 \mathrm{~m} /$ day in test 1 and $4-20 \mathrm{~m} /$ day in test 2

2. Dispersivity $(\alpha)$ :

a. in the alluvium $13 \mathrm{~m}$ in test 1 and $36 \mathrm{~m}$ in test 2

b. in the basalt/alluvium complex $23 \mathrm{~m}$ in test 1 and $8-21 \mathrm{~m}$ in test 2

Seepage velocity through the interbed sediments was estimated by comparing breakthrough times in a well finished above the B-C interbed and a lysimeter finished below the interbed. The well and the lysimeter are laterally proximal to each other so the difference in breakthrough times may be considered to represent vertical transport through the interbed material. This comparison yielded an estimated seepage velocity of between 0.03 and $0.13 \mathrm{~m}$ /day through the sediments of the B-C interbed. A second calculation based on breakthrough in well 212 estimated the seepage velocity through interbed sediments at $0.13 \mathrm{~m} /$ day.

These estimates of seepage velocity and dispersivity for the three geologic units at the VZRP are valuable as they allow comparison of flow behavior both within and between the two tracer tests. Test 1 parameters represent transport under relatively wet and quasi-steady state flow conditions whereas test 2 parameters provide information on transport under drier, transient flow conditions.

Summary:

1. Breakthrough curves (BTCs) have been collected from eight wells and three lysimeters from two separate tests and using three different tracers. Altogether the two tests have yielded 22 welldefined BTCs that have been analyzed quantitatively

2. BTCs represent transport to depths of between 15 and $80 \mathrm{~m}$ and over lateral distances ranging from 20 and $200 \mathrm{~m}$

3. BTCs represent transport through three geologic units, the surficial alluvium, interbed sediments and fractured basalt

4. Comparison of BTCs from the two tests allows analysis of the effects wetter vs. drier conditions, and transient vs. steady-state flow on flow and transport behavior

5. Comparison of the breakthrough of two conservative tracers allows analysis of mechanisms of mass transfer between multiple flow domains

6. Coupling of BTC's and hydraulic flow data analysis are improving conceptual and numerical flow and transport models

7. Related finding are also enlarged as thesis projects for C. Jones and E. Nicholes.

\section{Publications}

Baker, K. E., L.C. Hull, J. Bennett, S.L. Ansley, and G. Heath, 2004, Conceptual models of flow through a heterogeneous, layered vadose zone under a percolation pond, INEEL/EXT-04-01679, Idaho Falls.

Baker, K.E., T.M. McLing, L.S. Street, A.L. Schafer, S. Ansley, L.C. Hull, R.M. Holt, R.C. Roback, and C. Jones, 2005, A Research Park for Studying Processes in Unsaturated Fractured Media, Eos Transactions, AGU 86:15, 19. 
Nichols E., Y. Asmerom, R.C. Roback, and C.L. Jones, 2005, Examining water-rock interaction at the Idaho National Engineering and Environmental Laboratory using uranium and strontium isotopes as natural environmental tracers: Abstract 2031: 15th Annual Goldschmidt Conference 2005.

Roback, R. C., C.L. Jones, L.C. Hull, T.L McLing, K.E. Baker, A.I. Abdel-Fattah, J.D. Adams, and E.M. Nichols, 2003, Transport Studies at the Vadose Zone Research Park, Idaho National Engineering and Environmental Laboratory: Results of Initial Tests, Eos Trans. AGU, 84(46), Fall Meet. Suppl., Abstract H32A-0521 (LA-UR-03-3439).

Jones, C.L., Roback, R.C., Reimus, P.W., Turin, H.J., Nichols, E.W., McLing, T.L., Baker, K.E., Hull, L.C. (2004). Flow and transport in a heterogeneous, layered vadose zone at the Vadose Zone Research Park, Idaho National Engineering and Environmental Laboratory: Initial results of tracer tests. Presented at the annual Geological Society of America meeting, Denver, CO 